\title{
CONSÓRCIO DE ESPÉCIES NATIVAS DA MATA ATLÂNTICA COM MILHO E FEIJÃO PARA REVEGETAÇÃO DE MATA CILIAR NA REGIÃO NOROESTE FLUMINENSE
}

\author{
Tiago José Freitas de Oliveira ${ }^{1 *}$, Deborah Guerra Barroso ${ }^{2}$, Aluísio Granato de Andrade ${ }^{3}$, Sílvio de Jesus Freitas ${ }^{2}$ \\ ${ }^{1}$ Universidade Estadual do Norte Fluminense, Programa de Pós-Graduação em Produção Vegetal, Campos dos Goytacazes, Rio de Janeiro, \\ Brasil - freitastj@yahoo.com.br* \\ ${ }^{2}$ Universidade Estadual do Norte Fluminense, Campos dos Goytacazes, Rio de Janeiro, Brasil - deborahbarroso@gmail.com; \\ freitassj@yahoo.com.br \\ ${ }^{3}$ Embrapa Solo, Rio de Janeiro, Rio de Janeiro, Brasil - aluisio.granato@ gmail.com
}

Recebido para publicação: 03/08/2015 - Aceito para publicação: 07/06/2016

\begin{abstract}
Resumo
Cultivos consorciados surgem como alternativa para a implantação ou manutenção da recuperação de matas ciliares. Este estudo teve como objetivo comparar o plantio misto de espécies arbóreas, com o sistema Taungya, na revegetação de mata ciliar do rio Paraíba do Sul, região noroeste fluminense, bem como o comportamento das espécies pioneiras e não pioneiras. Foi determinado ainda o impacto econômico da consorciação na restauração de matas ciliares nos primeiros nove meses após a implantação. Os tratamentos foram dispostos em blocos ao acaso, com dois sistemas de plantio em 4 repetições. O sistema de Taungya consistiu no cultivo de espécies agrícolas nas entrelinhas das espécies arbóreas. Foram avaliados altura, diâmetro à altura do colo, diâmetro de copa, cobertura de copas, índice de sobrevivência e impacto econômico da consorciação na recuperação de matas ciliares. Não foi observada influência dos sistemas de plantio convencional e Taungya no incremento relativo em altura e em diâmetro à altura do colo para a maioria das espécies arbóreas avaliadas, oito meses após o plantio. As espécies pioneiras apresentaram maior área de copa e consequente cobertura de área, em relação às espécies tardias, nos dois sistemas. No sistema Taungya, a receita obtida a partir da produção agrícola no primeiro ano de implantação do experimento representou $13 \%$ do custo total de implantação do projeto de reflorestamento.

Palavras-chave: Sistemas Agroflorestais; Taungya; área degradada.
\end{abstract}

\begin{abstract}
Intercropping native tree species of atlantic forest with corn and bean for restoration of riparian forest in northwest region fluminense. Intercropping crops emerge as an alternative to implementation or maintaining recovery riparian forest. This study aimed to compare the mixed planting of tree species, with Taungya system on riparian forest revegetation of the Paraiba do Sul River, Northwest Fluminense region, as well as the behavior of the pioneer and non-pioneer species. It was determined yet the intercropping economic impact of the riparian forests restoration in the first nine months after implantation. The treatments were arranged in random blocks with two planting systems in 4 repetitions. The Taungya system consisted of the cultivation of agricultural species between the lines of tree species. We evaluated height, diameter at the neck, crown diameter, canopy cover, survival rate and intercropping economic impact of the riparian forests recovery. There was no influence of conventional planting system and Taungya on the relative increase in height and diameter at neck height for most evaluated tree species, eight months after planting. The pioneer species have greater canopy area and consequently larger area coverage, compared to late species in both systems. In Taungya system, the revenue from the agricultural production in the first year of experiment deployment represented $13 \%$ of the total cost of reforestation project.
\end{abstract}

Keywords: Agroforestry systems; Taungya; degraded area.

\section{INTRODUÇÃO}

Ações que promovam a recuperação de matas ciliares têm sido apontadas como uma das mais importantes ferramentas para a conservação da natureza. No entanto, projetos para recuperação dessas áreas exigem elevados investimentos, motivo pelo qual necessitam de estudos com o objetivo de evitar possíveis equívocos que possam levar ao fracasso dessas ações e a prejuízos técnicos e econômicos (RODRIGUES et al., 2007).

A recuperação de matas ripárias, quando consolidadas, é considerada obrigatória em percentuais que variam conforme o tamanho da propriedade em que se inserem. Entretanto, na maioria das vezes, o cumprimento

FLORESTA, Curitiba, PR, v. 46, n. 3, p. 315 - 324, jul. / set. 2016.

Oliveira, T. J. F. de et al.

ISSN eletrônico 1982-4688

DOI: $10.5380 /$ rf.v46i3.42404 
dessas exigências não alcança a efetiva reconstrução ou perpetuação de uma floresta com espécies nativas, isso porque não são realizadas as ações indicadas, ou os métodos empregados são inadequados.

A busca de alternativas para a revegetação por meio de práticas de baixo custo que gerem renda, garantindo a preservação a partir da integração entre preservação e produção, é uma importante ferramenta para o convencimento e facilitação do trabalho junto aos produtores rurais (RODRIGUES et al., 2007), bem como para o sucesso da prática. O uso de sistemas agroflorestais (SAF's) como alternativa para a implantação ou manutenção da recuperação de matas ciliares, com uso temporário do espaço entre as espécies florestais nativas para o plantio de culturas como milho e feijão, pode reduzir os custos da implantação, por auxiliar no controle de plantas daninhas e permitir o retorno econômico (TAVARES, 2008). Espera-se ainda que as espécies florestais possam ser beneficiadas pelos tratos culturais dispensados às espécies agrícolas.

Classificada como prática agroflorestal, o sistema denominado Taungya, quando comparado ao sistema tradicional de cultivo, apresenta melhores resultados dos pontos de vista econômico, social e ambiental. Segundo Nair (1993), esse sistema consiste no consórcio entre árvores e culturas agrícolas por curto período de tempo, no qual as culturas agrícolas permanecem no sítio até que o sombreamento das copas das árvores permita a produção. A partir de sua adoção, é possível reduzir custos com tratos culturais, auxiliar no controle da erosão e da luminosidade e aumentar a concentração de matéria orgânica do solo, gerando assim sustentabilidade para o sistema e, ao mesmo tempo, possibilitando renda em médio e longo prazo (VARELLA, 2003).

Muitos estudos foram desenvolvidos a partir da consorciação entre cultivos agrícolas e cultivos florestais comerciais (VIANA et al., 2010; ALMEIDA et al., 2014), bem como com relação ao uso de diferentes formas de associação de culturas agrícolas e espécies florestais em reflorestamentos para restauração (DARONCO et al., 2012; SILVA et al., 2012; SOUZA; PIÑA-RODRIGUES, 2013), indicando retorno econômico significativo e resultados positivos.

Este estudo teve como objetivo comparar o crescimento e sobrevivência das espécies arbóreas cultivadas em sistema convencional de plantio e em Taungya (consórcio de espécies arbóreas, milho e feijão), em um reflorestamento de mata ciliar do rio Paraíba do Sul, região noroeste fluminense, e determinar o impacto econômico da consorciação na restauração de matas ciliares.

\section{MATERIAL E MÉTODOS}

\section{Local do estudo}

O experimento foi conduzido no Campo Experimental da Universidade Estadual do Norte Fluminense (UENF), em Itaocara, RJ. O município de Itaocara, localizado na região noroeste fluminense, nas coordenadas centrais $21^{\circ} 40^{\prime} 09^{\prime \prime} \mathrm{S}$ e $42^{\circ} 04^{\prime} 34^{\prime \prime} \mathrm{W}$, possui altitude em torno de $60 \mathrm{~m}$ e clima tropical seco (Aw), relacionado com a vegetação de Floresta Estacional Semidecidual (IBGE, 2012). A área experimental está localizada a $30 \mathrm{~m}$ da margem do rio Paraíba do Sul, no seu encontro com o rio Pomba. Trata-se de uma área inicialmente ocupada por pastagem degradada, formada principalmente por gramíneas e arbustos de pequeno porte, estabelecidas no local há pelo menos dez anos. As parcelas experimentais ocuparam uma faixa marginal de $190 \mathrm{~m}$, partindo da margem direita do rio Paraíba do Sul. A temperatura média anual varia entre 23 e $25^{\circ} \mathrm{C}$ e a precipitação pluviométrica é de 1000 a $1200 \mathrm{~mm}$ anuais, concentrados nos períodos de outubro-novembro a março-abril.

\section{Delineamento experimental}

Com o objetivo de avaliar e identificar técnicas de recuperação de áreas ciliares degradadas, em sua fase inicial, visando à adequação ambiental de propriedades rurais, foram comparados dois tratamentos: o plantio convencional de espécies nativas, realizado em espaçamento $3 \times 3 \mathrm{~m}$, e o Taungya, composto pelo plantio de espécies florestais, em espaçamento $3 \times 3 \mathrm{~m}$, consorciadas com milho e feijão. Os tratamentos foram dispostos em blocos ao acaso, com 2 sistemas de plantio (tratamentos) e 4 repetições. Foram adotadas parcelas de 21 x $24 \mathrm{~m}$.

Em abril de 2013, foram plantadas 56 mudas de árvores em cada parcela. Esse plantio, no sistema convencional e no sistema Taungya, teve como base o modelo sucessional em linhas, com as espécies nativas dispostas em linhas e alternadas conforme o grupo sucessional das pioneiras e não pioneiras. No sistema Taungya, foram trabalhados dois ciclos de produção para os componentes agrícolas. O primeiro ciclo, de abril a julho de 2013, foi representado pelo cultivo de feijão "xamego" nas entrelinhas das espécies florestais (Figura 1A). Foi respeitado $0,5 \mathrm{~m}$ em cada lado das espécies florestais sem o plantio do feijão, buscando-se diminuir a competição entre as espécies.

No segundo ciclo, de setembro de 2013 a janeiro de 2014, foi realizado, nas entrelinhas das espécies florestais (Figura 1B), consórcio entre milho híbrido UENF 506-11 e uma variedade de feijão preto com crescimento do tipo determinado. 


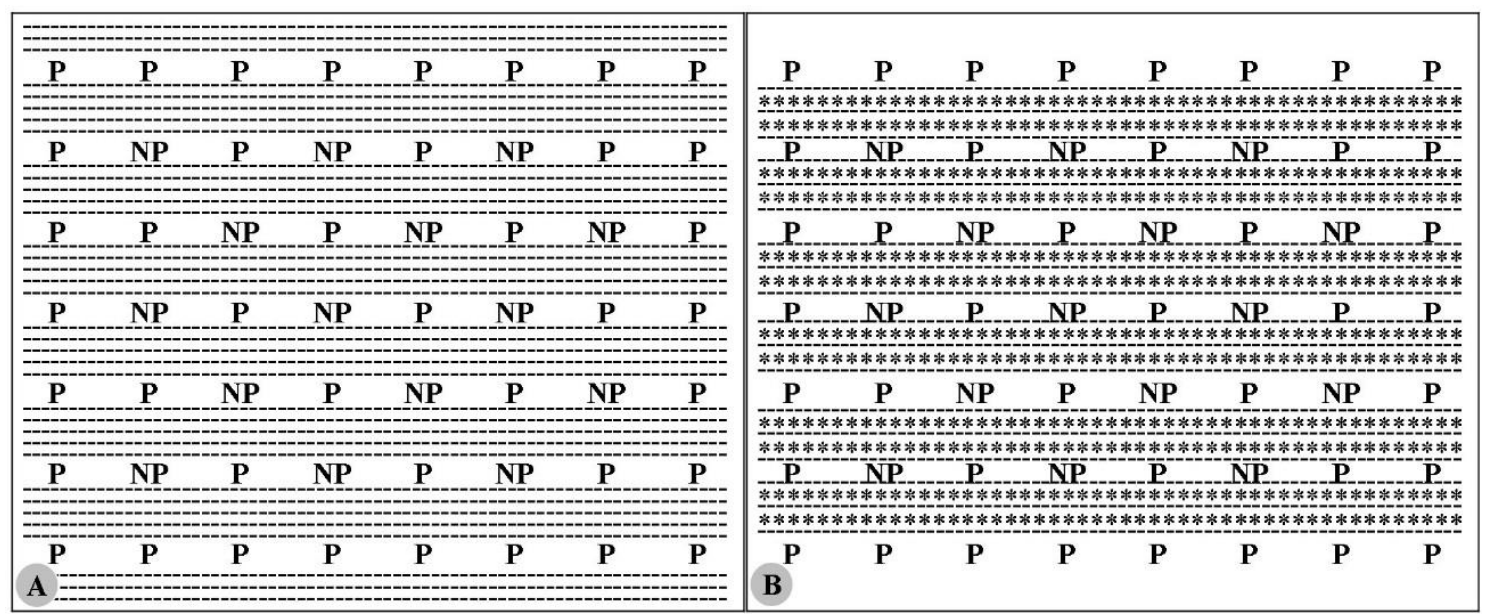

Figura 1. Esquema de plantio do sistema Taungya. (A) Primeiro ciclo de produção, com as espécies arbóreas nativas em consórcio com feijão "chamego" (----). (B) segundo ciclo de produção, com as espécies arbóreas nativas em consórcio com feijão preto (----) e milho híbrido UENF 506-11 (*****). P = espécie florestal pioneira e NP = espécie florestal não pioneira.

Figure 1. Taungya system of planting scheme. (A) First production cycle, with native tree species intercropped with beans "Xamego" (----). (B) second production cycle, with native tree species in consortium with black beans (---- ) and hybrid corn UENF 506-11 (****). P = pioneer tree species and NP = not pioneer tree species.

A área, inicialmente dominada por capim braquiária (Brachiaria sp. - Syn. Urochloa sp.) e capim colonião (Panicum maximum), foi roçada para diminuir a infestação das gramíneas dominantes na área. $\mathrm{O}$ plantio das espécies florestais nativas se iniciou 30 dias após a roçada inicial da área experimental. As covas, com dimensões de $40 \mathrm{~cm}$ de diâmetro e $40 \mathrm{~cm}$ de profundidade, foram abertas com perfurador de solo acoplado a um trator. Após abertura das covas foi realizada adubação de plantio com $250 \mathrm{~g} /$ cova de superfosfato simples.

O plantio do feijão "chamego" no primeiro ciclo de produção foi realizado dez dias após o plantio das espécies florestais, com matraca (plantadora e adubadora). O espaçamento entre linhas foi de 0,4 m, com nove sementes por metro de linha de plantio. $O$ estande final em cada parcela de $504 \mathrm{~m}^{2}$ foi de aproximadamente 7.560 plantas. Foi mantido $0,5 \mathrm{~m}$ em cada lado das espécies florestais nativas sem o plantio da cultura agrícola. Foi feito preparo convencional do solo, com grade acoplada em trator. No primeiro ciclo, foi realizada adubação de plantio com $5 \mathrm{~g} /$ cova de superfosfato simples.

O segundo ciclo de produção foi iniciado cinco meses após o primeiro, sendo a semeadura realizada com matraca. Esse consórcio contou com duas linhas de milho e três linhas de feijão entre as linhas das espécies florestais nativas. As duas linhas de milho foram plantadas com entrelinha de $1 \mathrm{~m}$ e densidade de seis plantas por metro linear. A adubação foi realizada com $50 \mathrm{~g} / \mathrm{m}$ de NPK 04-14-08 na linha de plantio.

O feijão foi semeado com densidade de dez plantas por metro linear e a adubação foi realizada com $50 \mathrm{~g} / \mathrm{m}$ de superfosfato simples por metro na linha de plantio. O estande final do feijão foi de aproximadamente 4.320 plantas, e do milho, de 1.728 plantas por hectare.

O preparo do solo foi realizado de forma convencional, visando favorecer o desenvolvimento das culturas agrícolas. As demais atividades de preparo do solo e tratos culturais foram realizadas de acordo com as recomendações para a cultura do feijão e do milho (EMBRAPA, 2007).

As espécies florestais nativas utilizadas nos dois tratamentos (Tabela 1) foram adquiridas de viveirista em Campos dos Goytacazes. Essas espécies, segundo Martins (2007), são indicadas para recuperação de matas ciliares. Foram determinados altura e diâmetro médio das mudas na ocasião do plantio. 
Tabela 1. Espécies florestais nativas indicadas para reflorestamentos em matas ciliares, seguidas Médias ( \pm intervalo de confiança) das alturas e diâmetro à altura do colo das mudas utilizadas na implantação do experimento.

Table 1. Native species recommended for reforestation in riparian forest, followed Mean ( \pm confidence interval) of heights and diameters up to the lap of the seedlings used in the implementation of the experiment.

\begin{tabular}{|c|c|c|c|c|c|c|}
\hline \multirow{2}{*}{ Nome científico } & \multirow{2}{*}{ Nome vulgar } & \multirow{2}{*}{ Família } & \multicolumn{2}{|c|}{ Convencional } & \multicolumn{2}{|c|}{ Taungya } \\
\hline & & & Altura (m) & DAC (mm) & Altura (m) & DAC (mm) \\
\hline \multicolumn{7}{|l|}{ Pioneiras } \\
\hline Parapiptadenia rigida & Monjolo & abaceae & $0,59 \pm 0,10$ & $5,37 \pm 0,48$ & $0,65 \pm 0,07$ & $5,50 \pm 0,43$ \\
\hline Schinus terebinthifolius & Aroe & nacardiaceae & $0,55 \pm 0,10$ & $6,36 \pm 0,86$ & $0,62 \pm 0,06$ & $6,44 \pm 0,72$ \\
\hline Sapium glandulosum & Leiteira & uphorbiaceae & $0,86 \pm 0,06$ & $9,57 \pm 0,47$ & $0,79 \pm 0,09$ & $8,99 \pm 0,68$ \\
\hline Anacardium occidentale & Caju & nacardiaceae & $0,41 \pm 0,02$ & $6,69 \pm 0,46$ & $0,44 \pm 0,03$ & $6,58 \pm 0,43$ \\
\hline Psidium guajava & Goiaba & Iyrt & $0,52 \pm 0,14$ & $6,15 \pm 0,83$ & $0,54 \pm 0,15$ & $6,32 \pm 0,81$ \\
\hline \multicolumn{7}{|l|}{ Não Pioneiras } \\
\hline utangulum & & & $\pm 0,10$ & 14 & $0,58 \pm 0,17$ & 1,19 \\
\hline Genipa a & Jenip & ae & $42 \pm 0,10$ & ,96 & $0,45 \pm 0,05$ & 1,16 \\
\hline Caesalpinia ferrea & Pau-ferro & Fabaceae & $0,52 \pm 0,11$ & $6,61 \pm 0,79$ & $0,62 \pm 0,17$ & $5,47 \pm 1,15$ \\
\hline Campomanesia guazumifolia & Gabiroba & Myrtaceae & $0,81 \pm 0,18$ & $5,85 \pm 0,66$ & $0,80 \pm 0,18$ & $5,84 \pm 1,23$ \\
\hline Eugenia uniflora & Pitanga & Myrtaceae & $0,52 \pm 0,08$ & $5,51 \pm 0,81$ & $0,48 \pm 0,14$ & $5,81 \pm 1,93$ \\
\hline Piptocarpha macropoda & Mololô & Asteraceae & $0,47 \pm 0,10$ & $5,70 \pm 0,94$ & $0,55 \pm 0,08$ & $6,04 \pm 0,89$ \\
\hline Inga laurina & Ingá & Fabaceae & $0,49 \pm 0,10$ & $7,93 \pm 0,94$ & $0,46 \pm 0,08$ & $8,32 \pm 1,16$ \\
\hline
\end{tabular}

\section{Coleta e análise dos dados}

Foram realizadas duas medições da altura e do diâmetro à altura do colo (DAC) e uma medida de diâmetro da copa (DC) das mudas de espécies nativas, aos quinze dias e aos oito meses após o plantio. Aos oito meses após o plantio, também foi realizada a avaliação da sobrevivência. A altura e DC foram medidos com vara graduada, e o DAC, com paquímetro digital.

O DC foi obtido pela média do maior e do menor diâmetro de cada copa, a partir da qual foi calculada a área da copa. A cobertura de copas foi obtida pela razão entre o somatório das áreas de copa individuais e a área da parcela.

O índice de cobertura das copas foi utilizado para a comparação entre os tratamentos, inferindo-se sobre a eficiência dos mesmos no que diz respeito à cobertura do solo.

Foram comparados os incrementos em altura, diâmetro à altura do colo e sobrevivência das espécies entre os tratamentos, considerando-se o grupo ecológico de cada uma delas (pioneiras e não-pioneiras). Para análise da porcentagem de sobrevivência, os dados foram transformados em $\sqrt{ }(x+1 / 2)$, por estarem dentro do intervalo de 80 a 100\%, com denominador comum (ZIMMERMANN, 2004). Para cálculo dos incrementos relativos, foi utilizada a equação $(\mathrm{H} 2-\mathrm{H} 1) / \mathrm{H} 1$, sendo $\mathrm{H} 1$ a altura inicial e $\mathrm{H} 2$ a altura final.

Considerando que rendimentos econômicos são indicadores de sustentabilidade em SAF's, para a avaliação comparativa de custos e manejos entre o sistema Taungya e o reflorestamento convencional, as operações de implantação, plantio, manejo e colheita foram monitoradas, sendo os rendimentos operacionais registrados.

Os valores para mão de obra, insumos e horas/máquina foram obtidos em consulta a empresas que atuam no mercado regional. $\mathrm{O}$ valor de venda do feijão e do milho nos meses da colheita foram obtidos em consulta à CONAB (2014).

O primeiro ciclo do feijão foi colhido aos três meses após a implantação, e o segundo ciclo, 8 meses após implantação. Após beneficiamento do feijão, sua produção foi determinada por bloco e comparada com a produtividade da cultura na região. O ciclo do milho foi colhido 9 meses após implantação e, da mesma forma, os grãos foram beneficiados, com a produção obtida por bloco e comparada com a produtividade da cultura na região.

Foi determinada a produtividade efetiva, considerando a área efetiva de plantio agrícola, em cada ciclo. Essa produtividade foi comparada à produtividade potencial de grãos, que é aquela em que se considera a cultura agrícola ocupando $100 \%$ da área, encontrada para os cultivos agrícolas na região noroeste fluminense. Assim, foi calculado o retorno econômico dos cultivos agrícolas ao final de cada ciclo e o quanto es se retorno contribui para amortizar os custos de implantação dos sistemas propostos.

\section{RESULTADOS}

Não foi observada influência dos sistemas de manejo sobre a sobrevivência das espécies. Também não foi detectada influência dos sistemas de plantio convencional e do sistema Taungya no incremento relativo em 
altura e em diâmetro à altura do colo para a maioria das espécies arbóreas avaliadas, com exceção do incremento em altura da Campomanesia guazumifolia (gabiroba), que foi superior no sistema de plantio convencional (Figuras 2 e 3). Somente Schinus terebinthifolius (aroeira) apresentou melhores resultados no sistema Taungya, quanto à área de copa aos oito meses após plantio (Figura 4). Independentemente do sistema de manejo, as espécies pioneiras apresentaram maior área de copa e consequente cobertura de área, em relação às espécies tardias (Tabela 2).

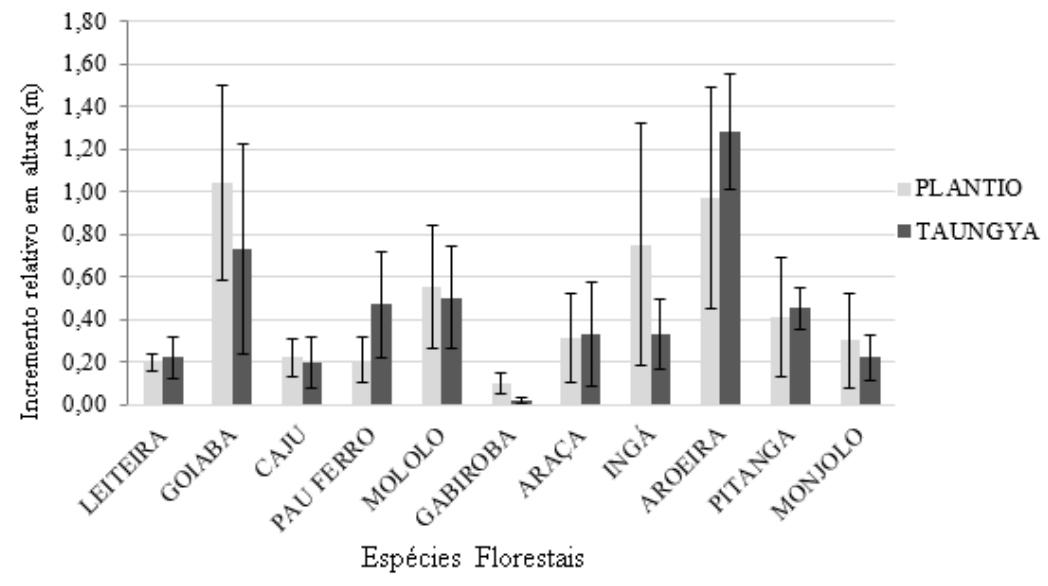

Figura 2. Valores médios de incremento relativo em altura das espécies florestais em dois sistemas (plantio convencional e Taungya), do plantio até o $8^{\circ}$ mês, na margem do rio Paraíba do Sul, no município de Itaocara, RJ. Barras representam o intervalo de confiança das médias (95\%).

Figure 2. Average values relative increment in height of the tree species in both systems (conventional planting and Taungya), from planting until the 8th month on the banks of the Paraiba do Sul river in the municipality of Itaocara, RJ. Bars represent averages of the confidence interval (95\%).

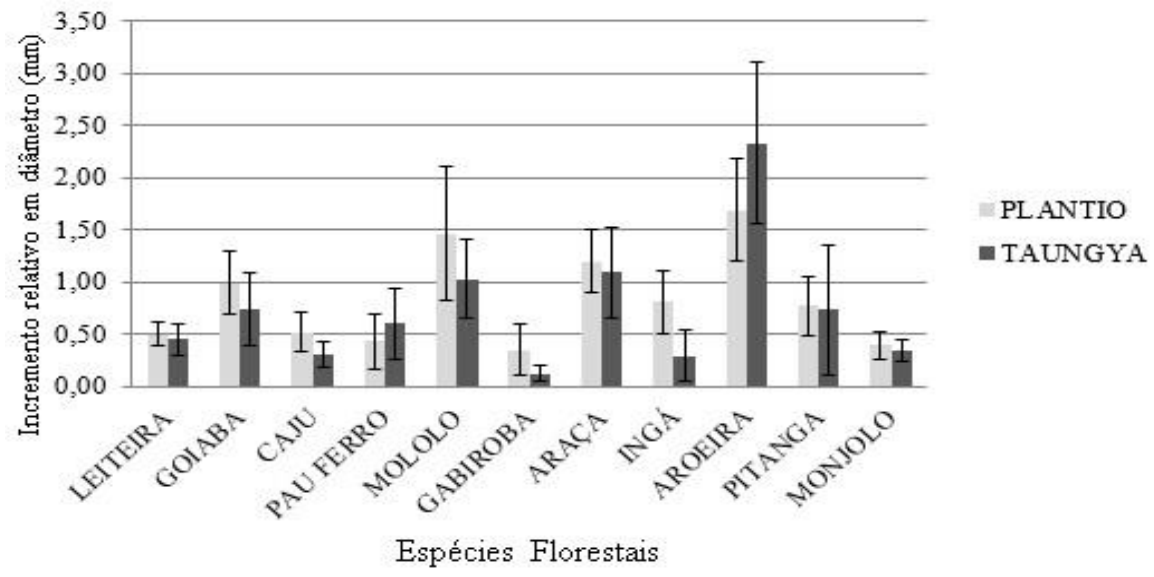

Figura 3. Valores médios de incremento relativo em diâmetro à altura do colo das espécies florestais em dois sistemas de manejo (plantio convencional e Taungya), aos 8 meses após o plantio na margem do rio Paraíba do Sul, no município de Itaocara, RJ. Barras representam o intervalo de confiança das médias (95\%).

Figure 3. Average values relative increment in diameter up to the lap of forest species in two management systems (conventional planting and Taungya), at 8 months after planting on the banks of the Paraiba do Sul River in the municipality of Itaocara, RJ. Bars represent averages of the confidence interval $(95 \%)$. 


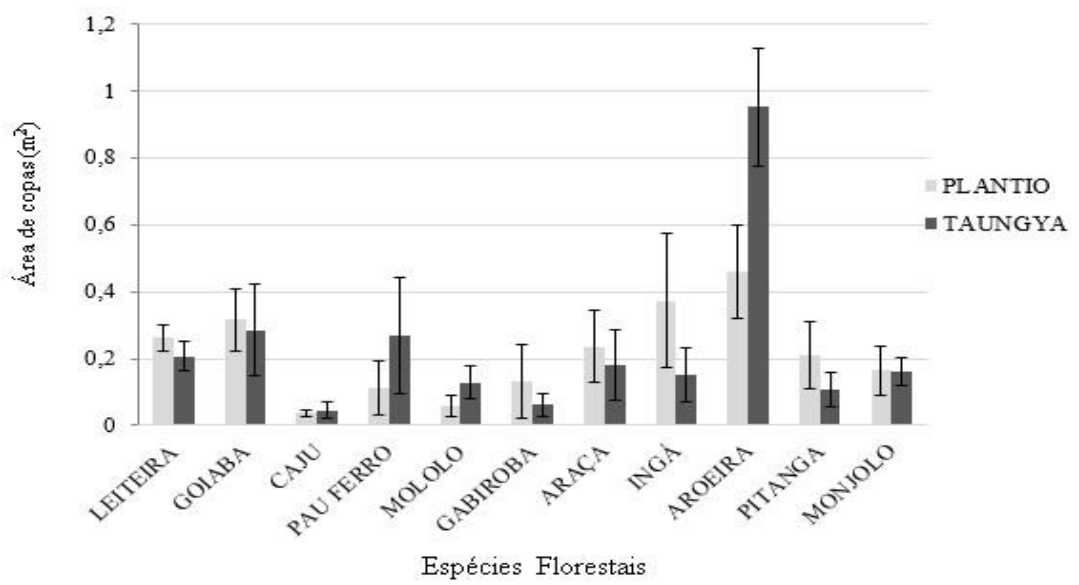

Figura 4. Valores médios de área da copa das espécies florestais nativas em dois diferentes sistemas (plantio convencional e Taungya), aos 8 meses após o plantio na margem do rio Paraíba do Sul, no município de Itaocara, RJ. Barras representam o intervalo de confiança das médias (95\%).

Figure 4. Cup area mean values of native forest species in two different systems (conventional planting and Taungya) at 8 months after planting on the banks of the Paraiba do Sul River in the municipality of Itaocara, RJ. Bars represent averages of the confidence interval (95\%).

Tabela 2. Valores médios de incremento relativo em altura (IRH) e em diâmetro à altura do colo (IRD), sobrevivência, área (AC) e cobertura de copas (CobC), considerando o grupo ecológico (Pioneiras e Não Pioneiras) entre os diferentes sistemas de manejos (Plantio convencional e Taungya). $\mathrm{P}=$ Pioneiras, $\mathrm{NP}=$ Não Pioneiras.

Table 2. Mean values relative increment in height (IRH) in diameter and up to neck (IRD), survival, area (AC) and canopy cover (CobC), considering the environmental group (Pioneer and Pioneer not) between the different management systems (conventional planting and Taungya). Pioneer $\mathrm{P}=\mathrm{NP}=$ Not Pioneer.

\begin{tabular}{lcccc}
\hline & \multicolumn{2}{c}{ Plantio } & \multicolumn{2}{c}{ Taungya } \\
\hline IRH & $\mathbf{P}$ & $\mathbf{N P}$ & $\mathbf{P}$ & NP \\
Média & 0,357 a & $0,360 \mathrm{a}$ & $0,382 \mathrm{a}$ & $0,316 \mathrm{a}$ \\
\cline { 2 - 5 } CV $(\%)$ & \multicolumn{2}{c}{$0,358 \mathrm{a}$} & $0,349 \mathrm{a}$ \\
\cline { 2 - 5 }
\end{tabular}

\begin{tabular}{|c|c|c|c|c|}
\hline IRD & $0,655 \mathrm{a}$ & $0,865 \mathrm{a}$ & $0,718 \mathrm{a}$ & $0,643 \mathrm{a}$ \\
\hline Média & \multicolumn{2}{|c|}{$0,76 \mathrm{a}$} & \multicolumn{2}{|c|}{$0,68 \mathrm{a}$} \\
\hline $\mathrm{CV}(\%)$ & \multicolumn{4}{|c|}{19,98} \\
\hline AC & $7,76 \mathrm{a}$ & $2,34 \mathrm{~b}$ & $10,67 \mathrm{a}$ & $1,92 \mathrm{~b}$ \\
\hline Média & \multicolumn{2}{|c|}{$5,05 \mathrm{a}$} & \multicolumn{2}{|c|}{$6,29 \mathrm{a}$} \\
\hline $\mathrm{CV}(\%)$ & & & & \\
\hline
\end{tabular}

\begin{tabular}{lrrrr}
\hline CobC & $1,54 \mathrm{a}$ & $0,46 \mathrm{~b}$ & $2,11 \mathrm{a}$ & $0,38 \mathrm{~b}$ \\
\cline { 2 - 4 } Média & \multicolumn{3}{c}{$1,0 \mathrm{a}$} & $2,24 \mathrm{a}$ \\
\cline { 2 - 4 } CV $(\%)$ & \multicolumn{3}{c}{28,94} \\
\hline
\end{tabular}

\begin{tabular}{|c|c|c|c|c|}
\hline \multirow{3}{*}{$\begin{array}{l}\text { Sobrevivência (\%) } \\
\text { Média } \\
\text { CV }(\%)\end{array}$} & $89.58 \mathrm{a}$ & $88.33 \mathrm{a}$ & $86.58 \mathrm{a}$ & $88.42 \mathrm{a}$ \\
\hline & \multicolumn{2}{|c|}{$88,95 \mathrm{a}$} & \multicolumn{2}{|c|}{$87,5 \mathrm{a}$} \\
\hline & \multicolumn{4}{|c|}{5,36} \\
\hline
\end{tabular}

Os custos de implantação e manutenção aos nove meses do plantio convencional foram de R $\$$ 8.292,55 por hectare (Tabela 3), e no sistema Taungya, o custo foi $88 \%$ maior (Tabela 3). O que diferencia os dois sistemas são as operações de plantio, manejo, colheita e os insumos (fertilizantes) gastos com os componentes agrícolas (milho e feijão) do sistema Taungya. 
Tabela 3. Custos para implantação, por hectare, até os 9 meses de idade, de reflorestamento nas margens do rio Paraíba do Sul, no município de Itaocara, RJ, com espécies arbóreas nativas em plantio convencional (A) e em consórcio com feijão e milho (B).

Table 3. Costs for deployment, per hectare, up to 9 months old, reforestation on the banks of the Paraiba do Sul river, in the municipality of Itaocara, RJ, with native tree species in conventional tillage and intercropping with beans and corn.

\begin{tabular}{|c|c|c|c|}
\hline \multicolumn{4}{|c|}{ A - Plantio convencional de espécies arbóreas } \\
\hline \multirow{2}{*}{ Variáveis } & \multirow{2}{*}{ Unidade } & \multirow{2}{*}{ Valor unitário (R\$) } & Ano 1 - implantação \\
\hline & & & Total $(\mathbf{R} \$)$ \\
\hline Operações mecanizadas & & & 316,80 \\
\hline Operações manuais & & & 715,50 \\
\hline Insumos & & & 626,21 \\
\hline Total (0,2 ha) & & & $1.658,51$ \\
\hline Total (ha) & & & $8.292,55$ \\
\hline \multicolumn{4}{|c|}{ B - Plantio de espécies arbóreas em consórcio com milho e feijão - Sistema Taungya } \\
\hline \multirow{2}{*}{ Variáveis } & \multirow{2}{*}{ Unidade } & \multirow{2}{*}{ Valor unitário $(\mathbf{R} \$)$} & Ano 1 - implantação \\
\hline & & & Total $(\mathbf{R} \$)$ \\
\hline Operações mecanizadas & & & 611,28 \\
\hline Operações manuais & & & 861,75 \\
\hline Insumos & & & $1.659,31$ \\
\hline Total (0,2 ha) & & & $3.132,34$ \\
\hline Total (ha) & & & $15.661,70$ \\
\hline
\end{tabular}

Considerando a produtividade média efetiva no primeiro ciclo do feijão (Tabela 4), pode-se afirmar que a produtividade do sistema não foi afetada pelo consórcio, uma vez que foram produzidos aproximadamente $86,8 \%$ do total esperado para o monocultivo, considerando uma lotação de $60 \%$ em relação à lotação do plantio solteiro. Por outro lado, a produção do feijão no segundo ciclo de cultivo foi afetada pelo consórcio entre as espécies arbóreas e agrícolas, principalmente por esse consórcio também ter sido realizado com o milho. Foram produzidos apenas $44,8 \%$ do total esperado em monocultivo para o estado do Rio de Janeiro. Da mesma forma, a produtividade do milho cultivado nesse segundo ciclo também foi afetada pelo consórcio, uma vez que foram produzidos aproximadamente $60 \%$ do total esperado para esse híbrido em monocultivo na região, considerando uma lotação de $57 \%$ em relação à lotação do plantio solteiro (Tabela 4).

Tabela 4. Produtividade média e receita das culturas agrícolas no sistema Taungya, nas margens do Rio Paraíba do Sul, no município de Itaocara, RJ.

Table 4. Average productivity of agricultural crops in Taungya system on the banks of the Paraiba do Sul river, in the municipality of Itaocara, RJ.

\begin{tabular}{|c|c|c|c|c|c|c|c|c|}
\hline \multicolumn{3}{|c|}{$\begin{array}{c}\text { Produtividade efetiva* } \\
\left(\mathrm{kg.ha}^{-1}\right)\end{array}$} & \multicolumn{3}{|c|}{$\begin{array}{c}\text { Produtividade potencial }{ }^{* *} \\
\left({\left.\mathrm{~kg} . \mathrm{ha}^{-1}\right)}^{-1}\right.\end{array}$} & \multicolumn{3}{|c|}{$\begin{array}{l}\text { Receitas }^{* * *} \\
\text { (R\$/ha) }\end{array}$} \\
\hline \multicolumn{2}{|c|}{ Feijão } & \multirow{2}{*}{$\begin{array}{c}\text { Milho } \\
2^{\circ} \text { ciclo } \\
\end{array}$} & \multicolumn{2}{|c|}{ Feijão } & \multirow{2}{*}{$\begin{array}{c}\text { Milho } \\
2^{\circ} \text { ciclo } \\
\end{array}$} & \multicolumn{2}{|c|}{ Feijão } & \multirow{2}{*}{$\begin{array}{c}\text { Milho } \\
2^{\mathbf{0}} \text { ciclo }\end{array}$} \\
\hline $1^{\circ}$ ciclo & $2^{\circ}$ ciclo & & $1^{\circ}$ ciclo & $2^{\circ}$ ciclo & & $1^{\circ}$ ciclo & $2^{\circ}$ ciclo & \\
\hline 498,67 & 147,00 & 1911,40 & 831,11 & 428,70 & 3344,88 & 1013,96 & 298,90 & 764,56 \\
\hline $\begin{array}{r}* \text { Conside } \\
\text { de } 85.71 \\
* * \text { Consid } \\
\text { o milho } \\
* * * \text { Feiião }\end{array}$ & $\begin{array}{l}\text { produção } \\
\text { lantas.ha }{ }^{-1} \text {; } \\
\text { a cultura a\& } \\
\$ 122,00\end{array}$ & $\begin{array}{l}\text { pécies agrí } \\
\text { o } 2^{\circ} \text { ciclo- }- \\
\text { a em } 100 \% \\
\text { de } 60 \mathrm{~kg} \text {; }\end{array}$ & $\begin{array}{l}\text { em consór } \\
\text { ção de } 34.2 \\
\text { rea, com un } \\
-\mathrm{R} \$ 24,0\end{array}$ & $\begin{array}{l}\text { Feijão } 1^{\circ} \mathrm{c} \\
\text { antas.ha }{ }^{-1} \text {; } \\
\text { inde final } \\
\text { ca de } 60 \mathrm{k}\end{array}$ & $\begin{array}{l}\text { - Lotação d } \\
0.000 \text { plant } \\
\text { nte: CONA }\end{array}$ & $\begin{array}{l}.000 \text { plant } \\
-1 \text { para o fe } \\
14)\end{array}$ & $\begin{array}{l}{ }^{1} \text {; Feijão } 2 \\
\text { de } 60.000\end{array}$ & $\begin{array}{l}\text { o - Lotação } \\
\text { tas.ha }^{-1} \text { para }\end{array}$ \\
\hline
\end{tabular}

A receita média obtida com o cultivo das espécies agrícolas no primeiro ano foi de $\mathrm{R} \$ 1.312,86$ para o feijão nos dois ciclos de cultivo e de $\mathrm{R} \$ 764,56$ para o milho, cultivado em consórcio com o feijão e as espécies florestais nativas no segundo ciclo de cultivo (Tabela 4). Sendo assim, a receita média total, obtida a partir da produção agrícola no primeiro ano de implantação do experimento, foi de R $\$ 2.077,42$ por hectare. Receita suficiente para abater cerca de $13 \%$ do custo total de implantação do sistema Taungya.

\section{DISCUSSÃO}

Uma indicação de que a utilização do consórcio entre espécies florestais e espécies agrícolas não foi prejudicial ao desenvolvimento inicial das árvores foi confirmada pela inexistência de diferenças para as

FLORESTA, Curitiba, PR, v. 46, n. 3, p. 315 - 324, jul. / set. 2016.

Oliveira, T. J. F. de et al.

ISSN eletrônico 1982-4688

DOI: $10.5380 /$ rf.v46i3.42404 
características dendrométricas avaliadas, entre os dois sistemas de manejos (Convencional e Taungya), exceto para a gabiroba, que apresentou maior incremento em altura no sistema convencional de plantio. Segundo Oliveira Neto et al. (2010), o plantio consorciado entre diferentes espécies agrícolas e florestais pode trazer prejuízos ao desenvolvimento destas, devido à competição por água, nutrientes e luz, promovida pela densidade inadequada de plantas por hectare introduzidas no sistema, o que não aconteceu no presente estudo.

A espécie Campomanesia guazumifolia (gabiroba), classificada como não pioneira (AQUINO; BARBOSA, 2010; AGUIAR et al., 2013), apresentou menor incremento relativo em altura (IRH) no sistema consorciado (Figura 2), podendo ter sofrido efeito competitivo. Por pertencer a estágios mais avançados da sucessão ecológica, essa espécie pode, ainda, ter sofrido maior interferência da luz solar, por meio da exposição direta das mudas no plantio.

Em diferentes estudos envolvendo reflorestamentos com mais de uma espécie ou em monocultivos, também não foram observadas diferenças significativas até o segundo ano após implantação entre os cultivos solteiros e consorciados, com relação à sobrevivência das espécies (SCHREINER; BALLONI, 1986; DARONCO et al., 2012). No que diz respeito à altura ou seu incremento relativo, outros trabalhos também encontram maiores valores para esses parâmetros, considerando-se as espécies arbóreas cultivadas em consórcio. (SCHREINER; BALLONI, 1986; SOUZA; PIÑA-RODRIGUES, 2013).

Segundo Gris et al. (2012), espécies pioneiras apresentam maior rusticidade, crescimento e robustez, características que podem favorecer o seu estabelecimento em áreas degradadas, quando comparadas com espécies de estágios mais avançados da sucessão ecológica. Não foi observada diferença no estabelecimento e no crescimento em diâmetro e altura entre os grupos ecológicos das pioneiras e não pioneiras utilizadas neste estudo, nos dois sistemas de manejos (plantio convencional e Taungya), entretanto a mais rápida cobertura da área em função do maior diâmetro de copa foi observada nas pioneiras em relação ao grupo das espécies tardias.

Souza et al. (2010), estudando o comportamento de espécies florestais em plantios a pleno sol e em faixas de enriquecimento de capoeira na Amazônia, observaram respostas distintas para as diversas espécies avaliadas nos dois sistemas de manejo. Esses autores sugerem uma seleção rigorosa das espécies a serem utilizadas em projetos de recuperação, conforme o manejo a ser adotado.

Schinus terebinthifolius (aroeira) foi a espécie que apresentou melhores respostas no sistema Taungya quanto à área apresentada por sua copa, aos oito meses após plantio (Figura 4), característica de grande importância em trabalhos de revegetação, confirmando sua aptidão (espécies pioneira) em promover o sombreamento necessário para o crescimento das outras espécies e também de propiciar uma melhor cobertura do terreno, que é essencial para a proteção dos solos. Independentemente do sistema de plantio, as espécies pioneiras apresentaram maior área de copa e, consequentemente, maior cobertura de área (Tabela 2). Segundo Jennings et al. (1999), a cobertura das copas controla a quantidade, qualidade e distribuição temporal e espacial da luz, determinando níveis diferenciados de umidade do ar, temperatura e condições de umidade do solo, além de promover a interceptação das chuvas, reduzindo o impacto direto sobre o solo. Sendo assim, o incremento da cobertura é fundamental para os processos de recuperação de matas ciliares degradadas, uma vez que a diminuição da luminosidade incidente no solo favorece, dentre outros fatores, o controle da mato-competição (RIBEIRO et al., 2012).

Durante os primeiros meses de avaliação do sistema consorciado, os custos com o reflorestamento foram, em parte, abatidos pelo cultivo intercalar do feijão e do milho, mesmo sendo observado que a produtividade média dos componentes agrícolas, no segundo ciclo de cultivo, foi afetada pelo consórcio, quando comparada à produtividade esperada para o estado do Rio de Janeiro (GABRIEL, et al., 2011; CONAB, 2014).

Este estudo ratifica outros trabalhos realizados com diferentes desenhos de consorciação entre árvores e culturas agrícolas (SCHREINER; BALLONI, 1986; SILVA et al., 2012; SANTOS et al., 2015), segundo os quais o plantio de culturas agrícolas em consórcio com espécies arbóreas permite que os gastos do reflorestamento sejam, em parte, ressarcidos pela comercialização dos produtos agrícolas associados. Por outro lado, a redução dos custos de implantação deste reflorestamento com o cultivo de milho e feijão no primeiro ano após a implantação foi inferior à redução obtida em outros trabalhos (SOUZA et al., 2007; DARONCO et al. 2012).

\section{CONCLUSÕES}

- Não foram observadas diferenças para a maioria das variáveis dendrométricas analisadas entre o plantio convencional de mudas e o sistema Taungya. Somente a espécie Campomanesia guazumifolia (gabiroba) apresentou menor incremento relativo em altura no sistema Taungya.

- Houve maior área de copa e cobertura de área por pioneiras com relação às espécies tardias, nos dois sistemas.

- A receita obtida a partir da produção agrícola no primeiro ano de implantação do experimento foi suficiente para abater $13 \%$ do custo total de implantação do sistema Taungya. 


\section{REFERENCIAS}

AGUIAR, R. V.; CANSIAN, R. L.; KUBIAK, G. B.; SLAVIERO, L. B.; TOMAZONI, T. A.; BUDKE, J. C.; MOSSI, A. J. Variabilidade genética de Eugenia uniflora L. em remanescentes florestais em diferentes estádios sucessionais. Revista Ceres, Viçosa, v. 60, n. 2, p. 226-233, 2013.

ALMEIDA, F. L. D.; CALONEGO, J. C.; TIRITAN, C. S.; ARAÚJO, F. F.; SILVA, P. C. G. D. Produtividade de soja em diferentes posições entre renques de eucalipto em cultivo consorciado. Colloquium Agrariae, v. 10, n. 1, p. 33-44, 2014.

AQUINO, C.; BARBOSA, L. M. Classes sucessionais e síndromes de dispersão de espécies arbóreas e arbustivas existentes em vegetação ciliar remanescente (Conchal, SP), como subsídio para avaliar o potencial do fragmento como fonte de propágulos para enriquecimento de áreas revegetadas no rio Mogi-Guaçu, SP. Revista Árvore, Viçosa, MG, v. 33, n. 2, p. 349-358, 2010.

CONAB, Companhia Nacional de Abastecimento. Acomp. Safra brasileira de grãos, v. 1 - Safra 2013/14, n. 4 Quarto Levantamento, Brasília, p. 1-67, 2014.

DARONCO, C.; MELO, A. C. G.; MACHADO, J. A. R. Consórcio de espécies nativas da floresta estacional semidecidual com mandioca (Manihot esculenta Crantz) para restauração de mata ciliar. Revista Árvore, Viçosa, MG, v. 36, n. 2, p. 291-299, 2012.

EMPRESA BRASILEIRA DE PESQUISA AGROPECUÁRIA (EMBRAPA). Agência de Informação EMBRAPA. Cultivo do Milho. 2007. Disponível em: 〈http://sistemasdeproducao.cnptia.EMBRAPA.br〉. Acesso em: 29 de maio de 2015.

GABRIEL, A. P. C.; PEREIRA, M. G.; GONÇALVES, L. S. A.; CUNHA, K. S.; RAMOS, H. C.; SOUZA FILHO, G. A.; AMARAL JUNIOR, A. T. Use of molecular markers in reciprocal recurrent selection of maize increases heterosis effects. Genetics and Molecular Research, v. 10, p. 2589-2596, 2011.

GRIS, D.; TEMPONI, L. G.; MARCON, T. R. Native species indicated for degraded area recovery in Western Paraná, Brazil. Revista Árvore, Viçosa, v. 36, n. 1, 2012.

INSTITUTO BRASILEIRO DE GEOGRAFIA E ESTATÍSTICA (IBGE). Manuais técnicos em geociências divulga os procedimentos metodológicos utilizados nos estudos e pesquisas de geociências. Av. Franklin Roosevelt, 166 - Centro - 0021-120 - Rio de Janeiro, RJ, Brasil. 2012.

JENNINGS, S. B.; BROWN, N. D.; SHEIL, D. Assessing forest canopies and understory illumination: canopy closure, canopy cover and other measures. Forestry, v. 72, n. 1, p. 59-73, 1999.

MARTINS, S. V. Recuperação de matas ciliares. Viçosa, MG. Ed. Aprenda Fácil, 2007. 255 p.

NAIR, P. K. R. An introduction to agroforestry. Dordrecht: Kluwer Academic, 1993. 513 p.

NOGUEIRA de SOUZA, Á.; SOARES SCOLFORO, J. R.; DONIZETTE de OLIVEIRA, A.; De MELLO, J. M.; PEREIRA de REZENDE, J. L. Viabilidade econômica de um sistema agroflorestal. Cerne, 13(1), p. 96-106. 2007.

OLIVEIRA NETO, S. N. de; VALE, A. B. do; NACIF, A. de P.; VILAR, M. B.; ASSIS, J. B. de; Sistema Agrossilvipastoril: integração lavoura, pecuária e floresta. Sílvio Nolasco de Oliveira Neto (Organizador). Viçosa, MG: Sociedade de Investigações Florestais, 2010.

RIBEIRO, P. R. C. C.; RIBEIRO, J. J.; NETO, A. R.; ROCHA, J. R. P.; CORTE, I. S. Métodos de recuperação de mata ciliar como proposta de recuperação de nascente no cerrado. Enciclopédia BIOSFERA, Centro Científico Conhecer, Goiânia, v. 8, n. 15, 2012.

RODRIGUES, E. R.; CULLEN, L. J.; BELTRAME, T. P.; MOSCOGLIATO, A. V.; SILVA, I. C. Avaliação econômica de sistemas agroflorestais implantados para a recuperação de Reserva Legal no Pontal do Paranapanema, São Paulo. Revista Árvore, v. 31, p. 941-948, 2007.

SANTOS, M. V.; SILVA, D. V.; FONSECA, D. M.; REIS, M. R.; FERREIRA, L. R.; OLIVEIRA NETO, S. N.; OLIVEIRA, F. L. R. Componentes produtivos do milho sob diferentes manejos de plantas daninhas e arranjos de plantio em sistema agrossilvipastoril. Ciência Rural, v. 45, n. 9, 2015.

SCHREINER, H. G.; BALLONI, E. A. Consórcio das culturas de feijão (Phaseolus vulgaris L.) e eucalipto (Eucalyptus grandis W. Hill ex Maiden) no Sudeste do Brasil. Bol. Pesq. Florestal, p. 83-104, 1986. 
SILVA, C. P. de C.; COELHO JUNIOR, L. M.; OLIVEIRA, A. D.; SCOLFORO, J. R. S.; REZENDE, J. L. P.; LIMA, I. C. G. Economic analysis of agroforestry systems with candeia. Cerne, Lavras, v. 18, n. 4, p. 585-594, 2012.

SOUZA, C. R.; AZEVEDO, C. P.; LIMA, R. M.; ROSSI, L. M. B. Comportamento de espécies florestais em plantios a pleno sol e em faixas de enriquecimento de capoeira na Amazônia. Acta Amazônica, v. 40(1), p. 127-134. 2010.

SOUZA, M. C. S.; PIÑA-RODRIGUES, F. C. M. Desenvolvimento de espécies arbóreas em sistemas agroflorestais para recuperação de áreas degradadas na Floresta Ombrófila Densa, Paraty, RJ. Revista Árvore, Viçosa-MG, v. 37, n. 1, p. 89-98, 2013.

TAVARES, S. R. L.; MELO, A. S.; ANDRADE, A. G.; ROSSI, C. Q.; CAPECHE, C. L.; BALIEIRO, F. C.; DONAGEMMA, G. K.; CHAER, G. M.; POLIDORO, J.; MACEDO, J. R.; PRADO, R. B.; FERRAZ, R. P. D. Curso de recuperação de áreas degradadas: a visão da ciência do solo no contexto de diagnóstico, manejo, indicadores de monitoramento e estratégias de recuperação. EMBRAPA Solos, 2008. Rio de Janeiro, RJ. Disponível em <http://www.infoteca.cnptia.embrapa.br/infoteca/handle/doc/340067>. Acesso em: 29 de maio 2015.

VARELLA, L. B. Sustentabilidade e prospectiva do sistema Taungya em comparação com a roça tradicional na Zona Bragantina do Estado do Pará. Movendo Ideias, v. 8, n. 14, p. 73-85, 2003.

VIANA, M. C. M.; MAGALHÃES, L. L.; QUEIROZ, D. S.; OFUGI, C.; MELIDO, R. C. N.; GOMES, R. J.; MASCARENHAS, M. H. T. Experiências com sistema de integração lavoura-pecuária-floresta em Minas Gerais. Informe Agropecuário, v. 31, n. 257, p. 98-111. 2010.

ZIMMERMANN, F. J. P. Estatística aplicada à pesquisa agrícola / Francisco José Pfeilsticker Zimmermann. Santo Antônio de Goiás: Embrapa Arroz e feijão, 2004. 402 p. 